\title{
Vitamin D and Dementia
}

\author{
T.J. Littlejohns ${ }^{1,2}$, K. Kos², W.E. Henley², E. Kuźma², D.J. Llewellyn²
}

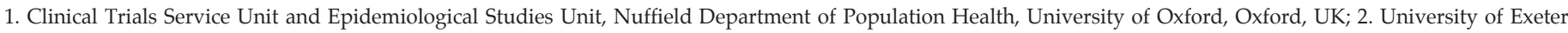
Medical School, University of Exeter, Exeter, UK

Corresponding Author: Dr. David J. Llewellyn, University of Exeter Medical School, College House, Heavitree Road, Exeter, UK, EX1 2LU, david.llewellyn@exeter.ac.uk

J Prev Alz Dis 2016;3(1):43-52

Published online June 1, 2015, http:/ / dx.doi.org/10.14283/jpad.2015.68

\begin{abstract}
Emerging evidence suggests that low vitamin D concentrations are potentially involved in the pathogenesis of dementia. This is of particular interest when considering the high prevalence of vitamin D deficiency in elderly adults and the urgent need to identify modifiable risk factors for dementia. Studies have found that vitamin D is implicated in procognitive and neuroprotective functions, including the reduction of Alzheimer's disease hallmarks such as amyloid beta and phosphorylated tau. Cross-sectional studies have consistently found that vitamin $\mathrm{D}$ concentrations are significantly lower in individuals with Alzheimer's disease and cognitive impairment compared to healthy controls. Longitudinal studies support an association between low vitamin $\mathrm{D}$ concentrations and an increased risk of dementia and cognitive decline. Neuroimaging studies are beginning to uncover the potential neurodegenerative and cerebrovascular mechanisms that underlie these associations such as white matter hyperintensities and enlarged ventricular volume, although there is currently a lack of longitudinal studies. In contrast to observational studies, findings from interventional studies have produced mixed results on the benefits of vitamin D supplementation on dementia and cognitive outcomes. Interpretation of the findings from these studies is hampered by several major methodological limitations, such as small sample sizes, inadequate doses and inclusion of participants unlikely to benefit from vitamin D supplementation. There is a need for large double-blind randomised-control trials investigating whether vitamin D supplementation can halt or delay the risk of dementia-related outcomes in individuals with low vitamin D concentrations.
\end{abstract}

Key words: Vitamin D, dementia, cognitive decline, neuroimaging.

\section{Background}

$\mathrm{D}$ ementia is currently recognised as a major public health priority on a worldwide scale. As a result of the ageing population, the estimated global prevalence of dementia cases is projected to treble from 35.6 million in 2010 to 115.4 million in 2050 (1). However, there is currently a lack of well-established modifiable risk factors to halt or delay the progression of the disease. Recently, vitamin D has emerged as a promising target for therapeutic intervention. The aim of this review is to provide an overview and discussion of the current state of evidence regarding vitamin D and dementia-related outcomes.

Vitamin D is a fat soluble steroid like hormone which has a well-established role in maintaining bone health by regulating calcium metabolism (2). It exists in two isoforms, vitamin D2 and D3. Around $90 \%$ of vitamin $\mathrm{D}$ is synthesised in the skin by the action of ultraviolet radiation from sunlight exposure on the cholesterol precursor, 7 -dehydrocholestorol $(2,3)$. Other sources include diet, including fortified foods, and supplementation (4). Vitamin D is initially biologically inert and requires two separate hydroxylation steps in order to be converted into its active form. First to 25-hydroxyvitamin D $(25(\mathrm{OH}) \mathrm{D})$ in the liver and then to the active hormonal form, 1,25-dihydroxyvitamin D in the kidney (5).

The major circulating form of vitamin D is $25(\mathrm{OH})$ $\mathrm{D}$ which can be measured in the serum and is a useful indicator of an individual's typical vitamin D status due to its half-life of around 15 days (6). Vitamin D status is defined using clinically relevant cut-points although there is some debate concerning which concentrations are optimal for general health $(7,8)$. Typically, vitamin $\mathrm{D}$ deficiency is defined as a $25(\mathrm{OH}) \mathrm{D}$ level of less than $50 \mathrm{nmol} / \mathrm{L}$, with severe deficiency defined as less than $25 \mathrm{nmol} / \mathrm{L}$ and insufficiency between 50 and $75 \mathrm{nmol} / \mathrm{L}$ (4). Based on these criteria approximately 1 billion individuals worldwide are either vitamin D deficient or insufficient (4). Elderly adults are particularly at risk of vitamin $\mathrm{D}$ deficiency for a variety of reasons, for example ageing reduces skin thickness resulting in a decrease in cutaneous concentrations of vitamin D3 precursor 7-dehydrocholesterol (9). Other reasons include a lack of adequate exposure to sunlight, decreased intake of vitamin $\mathrm{D}$ from diet, impaired intestinal absorption and impaired hydroxylation in the liver and kidney (10).

Emerging evidence suggests that vitamin D is involved in a wide variety of functions unrelated to bone health, such as immune function and vascular processes (11). Longitudinal studies have found that low vitamin D concentrations are also associated with an increased risk of colorectal cancer (12), type 2 diabetes (13) and cardiovascular disease (14). Furthermore, meta-analyses of randomised-controlled trials suggest that vitamin D 
supplementation reduces the risk of all-cause mortality (15). There is also increasing interest in the potential role of low vitamin D concentrations in the pathogenesis of cognitive decline, dementia and Alzheimer's disease (AD) (16-18). The next section provides an overview of the multiple functions that vitamin D has been implicated in throughout the brain from in vitro and in vivo studies.

\section{Vitamin D and the brain: animal studies and potential mechanisms}

\section{Vitamin $D$ in the central nervous system}

The central nervous system has been identified as a major target for vitamin D activity (5). The main vitamin $\mathrm{D}$ metabolites are present in the human cerebrospinal fluid (CSF), which circulates and surrounds the brain, and CSF concentrations are highly correlated with concentrations in blood plasma (19). Both the 1,25-dihydroxyvitamin D3 receptor and $1 \alpha$-hydroxylase, the enzyme responsible for synthesizing the bioactive form of vitamin D, are widely distributed throughout the human brain. Additionally, the vitamin D receptor and enzyme are densely located in areas associated with memory and higher order cognition, such as the CA1 and CA2 regions in the hippocampus as well as the dentate gyrus, cingulate gyrus and prefrontal cortex (20).

\section{Vitamin D and neurological functions}

Vitamin D has been implicated in neuroprotective functions and appears to play an important role in brain development. In vitro studies suggest that vitamin $\mathrm{D}$ is involved in neurotrophic support by inducing nerve growth factors and neurite outgrowth in embryonic rat hippocampal neurons (21). In contrast, rats born to vitamin D3 deficient mothers demonstrated a pronounced reduction in nerve growth factor in addition to decreased glial-derived neurotrophic factor compared to control rats (22). Furthermore, the vitamin D3 deplete rats experienced significant negative changes in brain development as well as more cell proliferation, which is indicative of an imbalance between cell mitosis and apoptosis (22). Similarly, in another study, rats born to vitamin D3 deficient mothers had larger lateral ventricles, reduced nerve growth factor content and reduced expression of genes involved in neuronal structure compared to controls at ten weeks of age (23). This provides evidence that the deleterious effects observed at birth on the rat brain persist into adulthood. Vitamin $\mathrm{D}$ has also been implicated in regulating neurotransmitter levels. Rats treated with neurotoxic doses of methamphetamine, had an attenuated depletion of serotonin and dopamine when given vitamin D compared to controls (24). In rats, vitamin $\mathrm{D}$ treatment resulted in increased activity in choline acetyltransferase, an enzyme involved in the synthesis of the acetylcholine neurotransmitter in specific brain nuclei (25). Furthermore, vitamin D had a drastic inhibitory effect on the expression of the inducible form of nitric oxide synthase in activated microglia and astrocytes in rats, an enzyme involved in the production of nitric oxide which is implicated in the brain's immune responses (26).

Changes in vitamin D regulated neuronal calcium $(\mathrm{Ca} 2+)$ status have been implicated in pathological processes associated with dementia and AD (27), with evidence of dysregulated L-Type voltagesensitive calcium channel (L-VSCC) function (28). In rodents, administration of 1,25-dihydroxyvitamin D promotes neuroprotection and reduces the $\mathrm{Ca} 2+$ mediated hippocampal biomarkers of aging through the downregulation of L-VSCC activity $(29,30)$. Serum $\mathrm{Ca} 2+$ concentrations are also regulated by parathyroid hormone $(\mathrm{PTH})$, which is in turn involved in the conversion of $25(\mathrm{OH}) \mathrm{D}$ to 1,25-dihydroxyvitamin D (31). Furthermore, vitamin D deficiency may lead to hyperparathyroidism which has been linked with non-skeletal health outcomes, such as the loss of muscle strength and mass (32) and sudden cardiac death (33). It is plausible that high PTH concentrations could mediate the association between low vitamin $\mathrm{D}$ concentrations and dementia-related outcomes. The evidence, mainly from poor quality cross-sectional studies, shows an inconsistent association between high PTH concentrations and poorer cognitive outcomes. (34-40).

\section{Vitamin $D$ and dementia related processes}

Animal and cellular studies have also implicated vitamin $\mathrm{D}$ in a variety of potential protective mechanisms that are associated with dementia and AD. In vitro, vitamin $\mathrm{D}$ increased the phagocytic clearance of amyloid plaques by stimulating macrophages obtained from AD patients $(41,42)$, and reduced amyloid induced cytotoxicity and apoptosis in primary cortical neurons in rat embryo neocortices (43). In aged rats, decline in learning and memory was ameliorated by vitamin D3 supplementation via a subcutaneous injection, whereas no improvement was observed in controls (44). Furthermore, in the same study, supplementation resulted in a decreased amyloid $\beta$ burden and an increased clearance of amyloid as well as a reduction in the pro-inflammatory cytokine, IL- $1 \beta$, and an increase in the anti-inflammatory cytokine, IL-10 (44). Similarly, vitamin $\mathrm{D}$ supplementation by subcutaneous injection in rats reduced cognitive decline and age-related tau phosphorylation (45). After surgery induced tissue damage to the liver, mice administered with vitamin D3 through an intraperitoneal injection, experienced a reduced risk of postoperative cognitive dysfunction which appeared to be mediated through the inhibition of inflammatory cytokines and molecules (46). In cortical cell cultures axon degeneration induced by amyloid $\beta$ 
peptide and glutamate was reduced by vitamin $\mathrm{D}$ given in combination with the N-methyl-D-aspartate receptor antagonist memantine (47).

\section{Vitamin D and cognitive decline: human observational studies}

\section{Cross-sectional studies}

Epidemiological studies have expanded on the findings from animal and cellular research by investigating whether vitamin D deficiency is associated with the development of cognitive disorders in elderly adults. Several systematic reviews and meta-analyses of cross-sectional and case-control studies have found that low serum vitamin D concentrations are consistently associated with prevalent cognitive impairment, AD, and dementia (48-51). The most recent meta-analysis found that in seven case-control studies serum $25(\mathrm{OH})$ $\mathrm{D}$ concentrations were 1.4 standard deviations lower in a total of $357 \mathrm{AD}$ patients compared to 648 controls (49). Similarly, a meta-analysis of eight studies consisting of a total of 2,749 participants, found that those who were serum $25(\mathrm{OH}) \mathrm{D}$ deficient $(<50 \mathrm{nmol} / \mathrm{L})$ scored on average 1.2 points lower on the Mini-Mental State Examination, a test of global cognitive function, than those who were serum $25(\mathrm{OH}) \mathrm{D}$ sufficient $(\geq 50 \mathrm{nmol} / \mathrm{L})$ (48). However, findings from cross-sectional studies should be interpreted with caution as reverse causation remains a possibility. For example, lower vitamin D concentration may be the result of behavioural changes, such as dietary changes and reduced sunlight exposure due to the onset of dementia and cognitive impairment (52).

\section{Longitudinal studies - cognitive decline or impairment}

To address this issue, several prospective studies have investigated the association between low vitamin $\mathrm{D}$ concentrations in elderly adults and the risk of cognitive decline and impaired cognitive functioning. Six prospective studies have found that low vitamin D concentrations are significantly associated with an increased risk of either cognitive decline $(53-57)$ or reduced cognitive functioning (58). In contrast, in 1,604 men aged 65 years and older, there was a non-significant monotonic increase in the odds of global cognitive decline on the Modified Mini-Mental State Examination over a mean follow-up period of 4.6 years across vitamin D quartiles measured at baseline (59). Similarly, in 299 participants aged 85 years and older, there was no association between vitamin $\mathrm{D}$ tertiles and incident global cognitive impairment on the Standardized MiniMental State Examination over a 3 year period (60). However, a systematic review and meta-analysis on vitamin D concentrations and specific cognitive domains suggests a strong association between low vitamin D concentrations and a range of executive dysfunctions, such as impaired processing speed, mental shifting and information updating (50). Only a modest association was observed with episodic memory, although the few studies that explored this association were all crosssectional.

\section{Longitudinal studies - dementia}

Five studies have investigated the association between vitamin $\mathrm{D}$ and dementia-related outcomes in elderly adults, with four measuring serum $25(\mathrm{OH}) \mathrm{D}$ concentrations (61-65) and one measuring vitamin D dietary intake (66). In the latter study, in 498 women with a mean age of 79.8 years, increased vitamin D dietary intake was associated with a reduced risk of $\mathrm{AD}$ but not non-AD dementias over a 7 year follow-up period (66).

Three of the four studies that measured $25(\mathrm{OH}) \mathrm{D}$ concentrations found that higher $25(\mathrm{OH}) \mathrm{D}$ concentrations were associated with a reduced risk of dementia-related outcomes (61-63). In 40 high-functioning elderly women aged 75 years or older, severe vitamin D deficiency $(<25 \mathrm{nmol} / \mathrm{L})$ was associated with a higher risk of non$\mathrm{AD}$ dementias but not $\mathrm{AD}$ compared to non-severe vitamin D deficiency ( $\geq 25 \mathrm{nmol} / \mathrm{L}$ ) over 7 years (61). In contrast, in 10,186 individuals, severe vitamin D deficiency $(<25 \mathrm{nmol} / \mathrm{L})$ was associated with AD but not vascular dementia compared to those with vitamin D sufficiency over a median follow-up of 21 years (62). The first study consisted of a very small sample size which likely resulted in a lack of statistical power (61) whereas the second study relied on dementia diagnoses from unstandardized medical records which may have resulted in considerable misclassification (62). To address these limitations we performed our own analyses and investigated the association between serum $25(\mathrm{OH}) \mathrm{D}$ concentrations and comprehensive adjudicated all-cause dementia and $\mathrm{AD}$ diagnoses in 1,658 individuals over a follow-up of 5.6 years (63). We found that participants who were $25(\mathrm{OH}) \mathrm{D}$ deficient $(\geq 25-50 \mathrm{nmol} / \mathrm{L})$ at baseline had a 53\% increased risk of developing all-cause dementia and a $69 \%$ increased risk of developing AD compared to those who were $25(\mathrm{OH}) \mathrm{D}$ sufficient $(\geq 50$ $\mathrm{nmol} / \mathrm{L}$ ). Furthermore, participants who were severely deficient $(<25 \mathrm{nmol} / \mathrm{L})$, had more than double the risk of developing all-cause dementia and AD compared to those with sufficient concentrations. We also found strong evidence of a threshold effect, where the risk of developing all-cause dementia and AD increased markedly below concentrations of around $50 \mathrm{nmol} / \mathrm{L}$. Furthermore, the difference in dementia and $\mathrm{AD}$ risk by clinically relevant categories of serum $25(\mathrm{OH}) \mathrm{D}$ concentrations became apparent after 2-3 years.

However, in 133 hospitalized participants, with a mean age of 85.2 years, who were either cognitively normal 


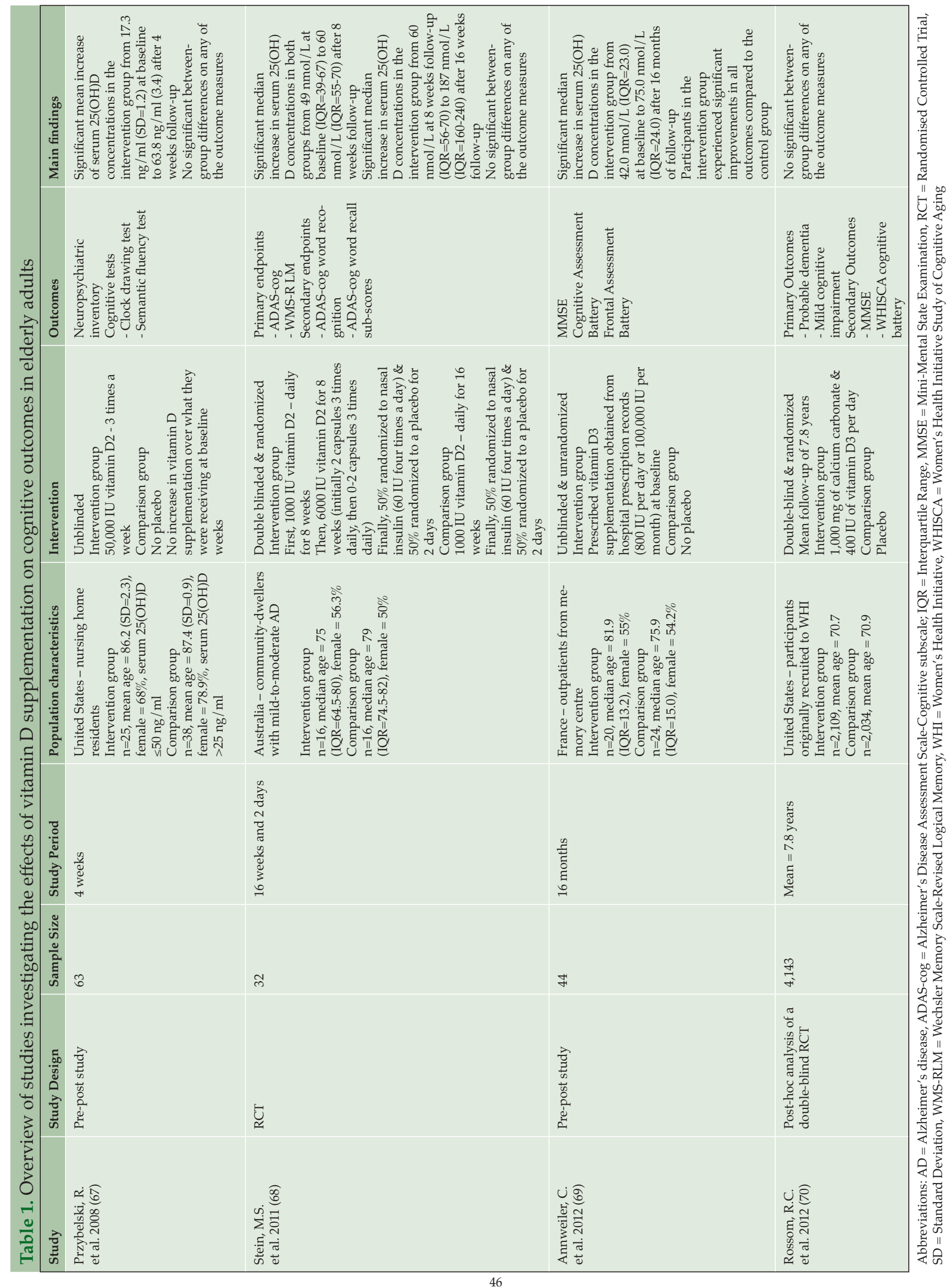


or had mild cognitive impairment (MCI) at baseline, $25(\mathrm{OH}) \mathrm{D}$ concentrations were not significantly associated with dementia conversion rates over a 2 year follow-up period (65). It should be noted that the study consisted of a small sample size and short follow-up period, whilst the inclusion of unhealthy participants limits the generalizability of the study findings.

\section{Vitamin $D$ and cognitive decline: interventional studies}

\section{Current interventional studies}

Four studies have investigated the effects of vitamin D supplementation on cognitive outcomes in elderly individuals (see Table 1), three were interventional studies (67-69) and one utilised a post-hoc design (70). Overall, three studies found that vitamin D supplementation did not improve either cognitive outcomes $(67,68,70)$ or reduce the risk of dementia/MCI compared to controls (70). In contrast, one study found that those who received vitamin D3 supplementation (800 IU per day or 100,000 IU per month) experienced improved global cognition and executive functioning abilities over a 16 month follow-up period compared to controls (69). However, methodological weaknesses such as small sample sizes (67-69), short follow-up periods $(67,68)$, lack of participant randomisation $(67,69)$ as well as heterogeneous doses of vitamin $\mathrm{D}$ supplementation and baseline vitamin $\mathrm{D}$ levels make it difficult to interpret the results of the interventional studies. The post-hoc study also has several major limitations (70). Through utilising a post-hoc design the study was not optimised to investigate the benefit of vitamin D supplementation on dementia risk. Additionally, the mean baseline 25(OH)D levels of $49 \mathrm{nmol} / \mathrm{L}$ were very close to $50 \mathrm{nmol} / \mathrm{L}$, a concentration that we observed in our study as a potential threshold for all-cause dementia and AD risk (63). Due to the relatively high serum $25(\mathrm{OH}) \mathrm{D}$ concentrations it is unlikely that many of these individuals were at an increased risk of developing dementia and therefore it is unsurprising that no significant difference was found in comparison with the placebo group. Finally, participants in the intervention group received only $400 \mathrm{IU} /$ day of vitamin D, which may be too low a dose to have an effect on dementia risk. Based on the lack of high quality clinical trials in the area it is clear that well-designed double blind randomised trials are necessary to investigate the potential of vitamin D supplementation to prevent or treat cognitive and dementia-related disorders.

\section{Ongoing interventional studies}

There are currently several ongoing trials in the area. The VITamin D and OmegA-3 Trial (VITAL) is a randomised, double-blind, placebo controlled trial in multi-ethnic healthy US participants which is investigating the effects of vitamin D and omega3 supplementation for the primary prevention of cancer over a period of 5 years (71). In the VITAL-COG ancillary study, cognitive decline is being measured as a secondary outcome in 3,226 men and women aged 60 or more. The study is utilising a $2 \times 2$ factorial design, with participants randomised to a combination of $2000 \mathrm{IU} /$ day of vitamin D3, $1 \mathrm{~g} /$ day omega-3 and a placebo. The primary endpoint of VITAL-Cog is a global composite score of cognitive decline, with two secondary endpoints measuring change over time in episodic memory and executive function score. The estimated completion date for the study is October 2017.

The DO-HEALTH study is another ongoing randomised, double-blind placebo controlled trial that aims to investigate whether a combination of $2000 \mathrm{IU} /$ day vitamin D, omega-3 and physical exercise can prevent disease with five primary endpoints, one of which is cognitive decline as assessed by the Montreal Cognitive Assessment. A total of 2,152 communitydwelling participants aged 70 years and older will be assigned to a group using a $2 \times 2 \times 2$ factorial design and will be followed for a 3 year period. Serum $25(\mathrm{OH}) \mathrm{D}$ concentrations will be measured at baseline as well as at 12,24 and 36 months to assess adherence to treatment. The estimated completion date for the study is June 2017.

\section{Vitamin $D$ and cognitive decline: neuroimaging studies}

Based on the available evidence from epidemiological studies it is plausible that vitamin D deficiency could be linked with pathological changes in the brain associated with neurodegenerative and cerebrovascular disorders (72). Furthermore, investigating the association between vitamin $\mathrm{D}$ concentrations and neuroimaging abnormalities could provide an insight into the potential mechanisms underlying the association with dementiarelated disorders.

As reviewed above, two animal studies have examined the effect of vitamin D deficiency on the structural development of the brain. Compared to control rats born to vitamin D3 sufficient mothers, rats born to vitamin D3 deficient mothers had a 30\% increase in hemisphere length, which suggests defected cortex development during embryogenesis (22). Moreover, vitamin D3 deficient pups had a $200 \%$ increase in lateral ventricle volume, which is indicative of atrophy in the surrounding regions. In a similar study, rats with transient vitamin D3 deficiency during early development demonstrated enlarged lateral ventricular volume in adulthood compared to control rats (23).

There have been several cross-sectional studies investigating the association between vitamin $D$ 


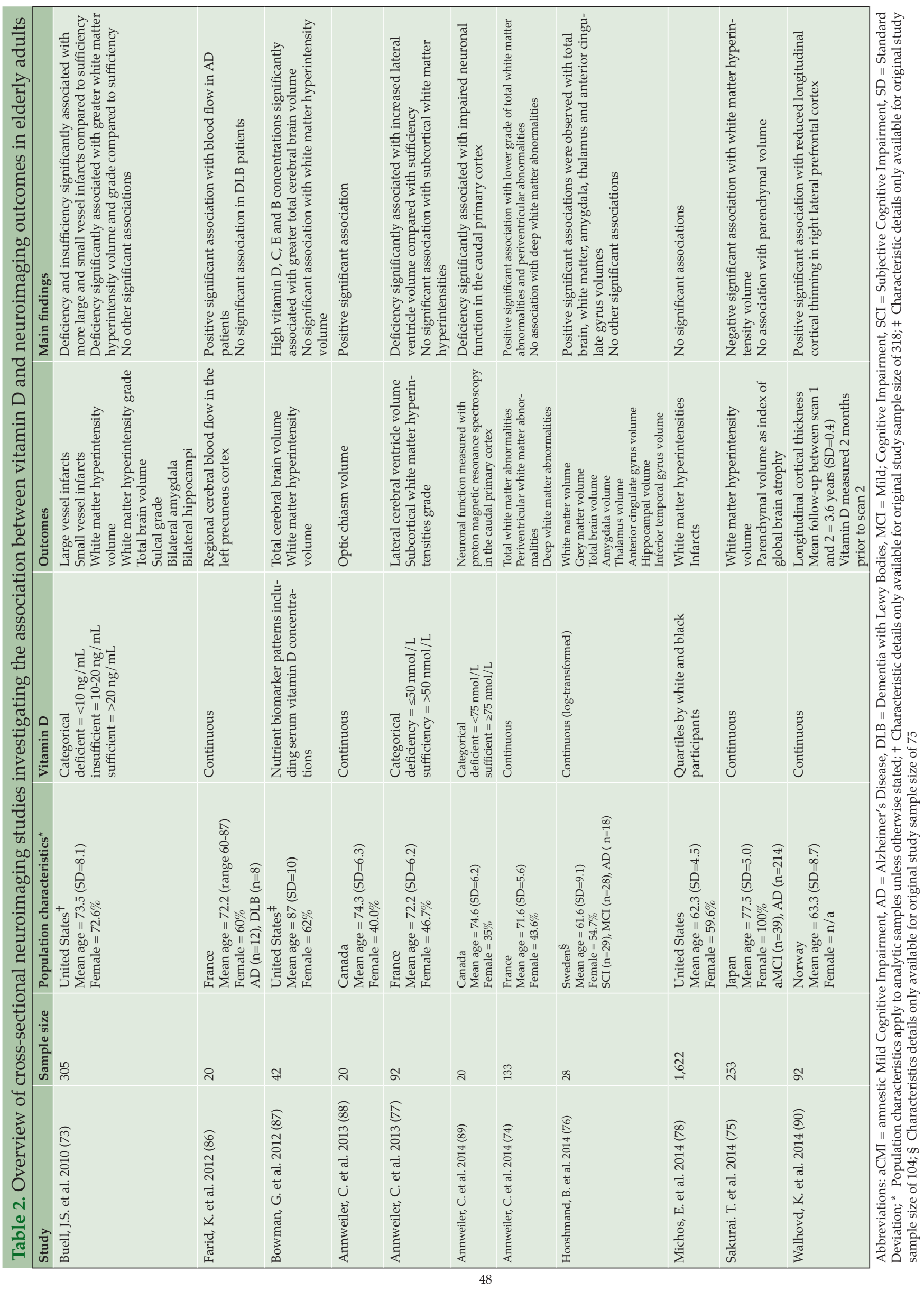


concentrations and a variety of structural neurological and cerebrovascular outcomes in elderly individuals (see Table 2). Overall, the available evidence from eleven cross-sectional studies appears to indicate that higher vitamin D concentrations are associated with a lower prevalence of neuroimaging abnormalities, particularly white matter hyperintensities (73-75), greater white matter volume (76) and decreased ventricular volume (77). It should be noted however that reverse causality remains a concern. As a result, prospective studies are necessary in order to determine the temporal relationship.

To date only one prospective study has investigated the association between baseline vitamin $D$ concentrations and the risk of developing future neuroimaging abnormalities in elderly adults (78). In 888 participants with a mean age of 62.3 years, lower vitamin D concentrations were not associated with change in white matter hyperintensity volume, incident white matter hyperintensities or incident infarcts over a follow-up period of approximately 10 years (78). The study also stratified the main analyses into black and white participants and found a similar lack of association. Whilst 888 participants at follow up is a large sample size, there was a high rate of participant drop out between the first MRI scan $(n=1,622)$ and the second MRI scan $(\mathrm{n}=888)$ which might have biased the findings through non-random attrition. Statistical methods to account for the missing data and non-random attrition might have helped to address this source of potential bias. In order to confirm the relationship of neurodegenerative and/ or cerebrovascular changes/impairments that underlie the association between vitamin $\mathrm{D}$ and dementia, further prospective studies are necessary.

\section{Limitations of current evidence and future aims}

There are several limitations of the current evidence base regarding vitamin $\mathrm{D}$ and its potential association with cognitive decline, dementia and AD. There is a lack of uniformity in the operationalization of vitamin $\mathrm{D}$ concentrations in observational studies, with a variety of different cut-points used to investigate the association with cognitive and neuroimaging outcomes. This is perhaps unsurprising considering there is an ongoing debate surrounding what the optimal vitamin $\mathrm{D}$ concentrations are for general health. In the US the Institute of Medicine (7) recommends serum 25(OH)D concentrations of $\geq 50 \mathrm{nmol} / \mathrm{L}$ as sufficient whereas the Endocrine Society (8) recommends concentrations $\geq 75$ $\mathrm{nmol} / \mathrm{L}$. There is a need to standardise clinically relevant $25(\mathrm{OH}) \mathrm{D}$ cut-points in order to aid the interpretation of the research literature.

Serum 25(OH)D concentrations have been measured using different techniques, mainly radioimmunoassay (RIA) or liquid chromatography-tandem mass spectrometry (LC-MS). These assays vary in precision and accuracy with evidence suggesting a low inter-assay comparability (79). A recent meta-analysis observed significant heterogeneity in the differences in vitamin $\mathrm{D}$ concentrations between $\mathrm{AD}$ patients and controls on the basis of the assay used (48). Whilst LC-MS is often considered as the 'gold standard' for measuring $25(\mathrm{OH})$ D concentrations (80), substantial variation has been observed when comparing within-assay results from the approach (81). Consequently, efforts are currently underway to ensure standardisation of serum $25(\mathrm{OH})$ $\mathrm{D}$ measurements across laboratories worldwide (82). There is also emerging evidence that free and bioavailable $25(\mathrm{OH}) \mathrm{D}$ might be a more reliable indicator of vitamin D status compared to total $25(\mathrm{OH}) \mathrm{D}$, although these findings have been in relation to bone mineral density $(83,84)$. It would be informative to investigate whether similar associations are observed in relation to dementiarelated outcomes.

A variety of different cognitive and dementia-related outcomes have been utilised. Cognitive function has been measured using a variety of different neuropsychological tests, which makes it difficult to synthesize the evidence. Long-term prospective studies have focused on either global cognitive function or executive functioning. There is a need for prospective studies to investigate the association between vitamin $\mathrm{D}$ and other cognitive domains, particularly memory which appears to be more weakly associated in cross-sectional studies. The majority of current prospective studies that have investigated the association with dementia-related outcomes have been limited by either small sample sizes $(61,65)$ or a reliance on medical records to inform dementia diagnosis (62). Large prospective studies which utilise comprehensive adjudicated dementia diagnoses as opposed to retrieving the diagnosis from medical records are necessary to explore the relationship with dementia-related outcomes, such as vascular dementia. Furthermore, prospective studies of longer duration exploring neuroimaging outcomes will provide useful insights into potential mechanisms as most current neuroimaging studies have been cross-sectional resulting in the possibility of reverse causation. Additionally, the findings from current crosssectional neuroimaging studies are difficult to interpret due to the wide range of methodologies and outcomes utilised. As new studies are published with comparable methods, a meta-analysis that synthesises common outcomes would be useful to clarify the relationship between vitamin $\mathrm{D}$ and neuroimaging abnormalities.

Prospective studies have found that low vitamin D concentrations are associated with a wide variety of non-skeletal diseases. However, intervention studies have so far failed to show a consistent benefit of vitamin D supplementation for cognitive and dementia-related outcomes. A recent systematic review concluded that the discrepancy in findings between observational and intervention studies is likely explained by low vitamin D concentrations being a marker of ill health as opposed 
to a causative factor (85). It should be noted that the associations observed in prospective observational studies regarding dementia and cognitive-related disorders do not support the possibility of reverse causation, given that there has been no interaction with baseline cognition observed (53), and the link with incident dementia was not driven by 'early converters' (those who developed dementia within a year of followup) (63). Ongoing trials will provide further insight into the issue of causation in relation to dementia-related outcomes, with results expected during 2017.

\section{Conclusion}

Evidence from animal and cellular studies suggests that vitamin D has multiple functions throughout the central nervous system and could be implicated in the prevention and treatment of disorders such as dementia and AD. Cross-sectional and case-control studies confirm that vitamin D concentrations are lower in individuals with cognitive impairment and dementia although reverse causality remains a possibility. To address this, longitudinal studies have found that low vitamin D concentrations are associated with an increased risk of cognitive decline, all-cause dementia and AD. Future neuroimaging studies may uncover a link with specific abnormalities that could explain the observed associations between vitamin $\mathrm{D}$ concentrations and dementia-related disorders. Clinical trials investigating the effect of vitamin D supplementation on cognitive outcomes have produced mixed findings; however a variety of methodological weaknesses limit the interpretability of these findings. Large double-blind, randomised, placebo controlled trials are currently ongoing and should provide results within the next few years. Taken together this body of evidence suggests that vitamin $\mathrm{D}$ is a promising therapeutic target in the prevention and treatment of dementia and AD.

\section{Conflict of interests: The authors have no conflicts of interests to disclose}

Funding: It was provided by NIRG-11-200737 from the Alzheimer's Association, the Mary Kinross Charitable Trust, the Halpin Trust, the Sir Halley Stewart Trust, the Age Related Diseases and Health Trust, the Rosetrees Trust (to D.J.L.) and the James Tudor Foundation (to D.J.L. and E.K.). This research was supported by the National Institute for Health Research (NIHR) Collaboration for Leadership in Applied Health Research and Care South West Peninsula at the Royal Devon and Exeter NHS Foundation Trust. The views expressed are those of the authors and not necessarily those of the NHS, the NIHR or the Department of Health. None of the funding sources had any role in the preparation of the manuscript.

\section{References}

1. Alzheimer's Disease International. World Alzheimer Report 2009. London; 2009.

2. DeLuca HF. Overview of general physiologic features and functions of vitamin D. Am J Clin Nutr. 2004;80:1689S - 1696S.

3. Holick MF. Vitamin D: a millenium perspective. J Cell Biochem. 2003;88:296307.

4. Holick MF. Vitamin D deficiency. N Engl J Med. 2007;357:266-81.

5. Deluca GC, Kimball SM, Kolasinski J, Ramagopalan S V, Ebers GC. The role of vitamin D in nervous system health and disease. Neuropathol Appl
Neurobiol. 2013;458-84.

6. Jones KS, Assar S, Vanderschueren D, Bouillon R, Prentice A, Schoenmakers I. Predictors of 25(OH)D half-life and plasma 25(OH)D concentration in The Gambia and the UK. Osteoporos Int. 2014;

7. (IOM), Institute of Medicine. Dietary Reference Intakes for Calcium and Vitamin D. Dietary Reference Intakes for Calcium and Vitamin D. Washington DC: National Academies Press; 2011.

8. Holick MF, Binkley NC, Bischoff-Ferrari HA, Gordon CM, Hanley DA, Heaney RP, Murad MH, Weaver CM. Evaluation, treatment, and prevention of vitamin D deficiency: an Endocrine Society clinical practice guideline. J Clin Endocrinol Metab. 2011;96:1911-30.

9. MacLaughlin J, Holick MF. Aging decreases the capacity of human skin to produce vitamin D3. J Clin Invest. 1985;76:1536-8.

10. Janssen HCJP, Samson MM, Verhaar HJJ. Vitamin D deficiency, muscle function, and falls in elderly people. Am J Clin Nutr. 2002;75:611-5.

11. Christakos S, Hewison M, Gardner DG, Wagner CL, Sergeev IN, Rutten E, Pittas AG, Boland R, Ferrucci L, Bikle DD. Vitamin D: beyond bone. Ann N Y Acad Sci. 2013;1287:45-58.

12. Gandini S, Boniol M, Haukka J, Byrnes G, Cox B, Sneyd MJ, Mullie P, Autie P. Meta-analysis of observational studies of serum 25-hydroxyvitamin D levels and colorectal, breast and prostate cancer and colorectal adenoma. Int J Cancer. 2011;128:1414-24.

13. Song Y, Wang L, Pittas AG, Del Gobbo LC, Zhang C, Manson JE, Hu FB. Blood 25-hydroxy vitamin D levels and incident type 2 diabetes: a metaanalysis of prospective studies. Diabetes Care. 2013;36:1422-8.

14. Wang L, Song Y, Manson JE, Pilz S, März W, Michaëlsson K, Lundqvist A, Jassal SK, Barrett-Connor E, et al. Circulating 25-hydroxy-vitamin D and risk of cardiovascular disease: a meta-analysis of prospective studies. Circ Cardiovasc Qual Outcomes. 2012;5:819-29.

15. Autier P, Gandini S. Vitamin D supplementation and total mortality: a metaanalysis of randomized controlled trials. Arch Intern Med. 2007;167:1730-7.

16. Soni M, Kos K, Lang IA, Jones K, Melzer D, Llewellyn DJ. Vitamin D and cognitive function. Scand J Clin Lab Invest Suppl. 2012;243:79-82.

17. Annweiler C, Dursun E, Féron F, Gezen-Ak D, Kalueff A V, Littlejohns T, Llewellyn DJ, Millet P, Scott T, et al. "Vitamin D and cognition in older adults": updated international recommendations. J Intern Med. 2014;

18. Schlögl M, Holick MF. Vitamin D and neurocognitive function. Clin Interv Aging. 2014;559-68.

19. Balabanova S, Richter HP, Antoniadis G, Homoki J, Kremmer N, Hanle J, Teller WM. 25-Hydroxyvitamin D, 24, 25-dihydroxyvitamin D and 1,25-dihydroxyvitamin D in human cerebrospinal fluid. Klin Wochenschr. 1984;62:1086-90.

20. Eyles DW, Smith S, Kinobe R, Hewison M, McGrath JJ. Distribution of the vitamin $\mathrm{D}$ receptor and 1 alpha-hydroxylase in human brain. J Chem Neuroanat. 2005;29:21-30.

21. Brown J, Bianco JI, McGrath JJ, Eyles DW. 1,25-dihydroxyvitamin D3 induces nerve growth factor, promotes neurite outgrowth and inhibits mitosis in embryonic rat hippocampal neurons. Neurosci Lett. 2003;343:139-43.

22. Eyles D, Brown J, Mackay-Sim A, McGrath J, Feron F. Vitamin d3 and brain development. Neuroscience. 2003;118:641-53.

23. Féron F, Burne THJ, Brown J, Smith E, McGrath JJ, Mackay-Sim A, Eyles DW Developmental vitamin D3 deficiency alters the adult rat brain. Brain Res Bull. 2005;65:141-8.

24. Cass WA, Smith MP, Peters LE. Calcitriol protects against the dopamine- and serotonin-depleting effects of neurotoxic doses of methamphetamine. Ann N Y Acad Sci. 2006;1074:261-71.

25. Sonnenberg J, Luine VN, Krey LC, Christakos S. 1,25-Dihydroxyvitamin D3 treatment results in increased choline acetyltransferase activity in specific brain nuclei. Endocrinology. 1986;118:1433-9.

26. Garcion E, Nataf S, Berod A, Darcy F, Brachet P. 1,25-Dihydroxyvitamin D3 inhibits the expression of inducible nitric oxide synthase in rat central nervous system during experimental allergic encephalomyelitis. Brain Res Mol Brain Res. 1997;45:255-67.

27. Mattson MP, Barger SW, Cheng B, Lieberburg I, Smith-Swintosky VL, Rydel RE. beta-Amyloid precursor protein metabolites and loss of neuronal Ca2+ homeostasis in Alzheimer's disease. Trends Neurosci. 1993;16:409-14.

28. Veng LM, Mesches MH, Browning MD. Age-related working memory impairment is correlated with increases in the L-type calcium channel protein alpha1D (Cav1.3) in area CA1 of the hippocampus and both are ameliorated by chronic nimodipine treatment. Mol Brain Res. 2003;110:193-202.

29. Brewer LD, Thibault V, Chen KC, Langub MC, Landfield PW, Porter NM. Vitamin D hormone confers neuroprotection in parallel with downregulation of L-type calcium channel expression in hippocampal neurons. J Neurosci. 2001;21:98-108.

30. Brewer LD, Porter NM, Kerr DS, Landfield PW, Thibault O. Chronic 1alpha,25-(OH)2 vitamin D3 treatment reduces Ca2+-mediated hippocampal biomarkers of aging. Cell Calcium. 2006;40:277-86.

31. Shoback D. Hypoparathyroidism. N Engl J Med. 2008;359:391-403.

32. Visser M, Deeg DJH, Lips P. Low vitamin D and high parathyroid hormone levels as determinants of loss of muscle strength and muscle mass (sarcopenia): the Longitudinal Aging Study Amsterdam. J Clin Endocrinol Metab. 2003;88:5766-72. 
33. Deo R, Katz R, Shlipak MG, Sotoodehnia N, Psaty BM, Sarnak MJ, Fried LF, Chonchol M, De Boer IH, et al. Vitamin D, parathyroid hormone, and sudden cardiac death: results from the Cardiovascular Health Study. Hypertension. 2011;58:1021-8.

34. Hagström E, Kilander L, Nylander R, Larsson E-M, Michaëlsson K, Melhus H, Ahlström H, Johansson L, Lind L, Ärnlöv J. Plasma parathyroid hormone is associated with vascular dementia and cerebral hyperintensities in two community-based cohorts. J Clin Endocrinol Metab. 2014;99:4181-9.

35. Björkman MP, Sorva AJ, Tilvis RS. Does elevated parathyroid hormone concentration predict cognitive decline in older people? Aging Clin Exp Res. 2010;22:164-9.

36. Johansson P, Almqvist EG, Johansson J-O, Mattsson N, Andreasson U, Hansson O, Wallin A, Blennow K, Zetterberg H, Svensson J. Cerebrospinal fluid (CSF) 25-hydroxyvitamin D concentration and CSF acetylcholinesterase activity are reduced in patients with Alzheimer's disease. PLoS One. 2013;8:e81989.

37. Kipen E, Helme RD, Wark JD, Flicker L. Bone density, vitamin D nutrition, and parathyroid hormone levels in women with dementia. J Am Geriatr Soc. 1995;43:1088-91.

38. Ogihara T, Miya K, Morimoto S. Possible participation of calcium-regulating factors in senile dementia in elderly female subjects. Gerontology. 1990;36 Suppl 1:25-30.

39. Shore D, Wills MR, Savory J, Wyatt RJ. Serum parathyroid hormone concentrations in senile dementia (Alzheimer's disease). J Gerontol. 1980;35:656-62.

40. Kalaitzidis RG, Karasavvidou D, Tatsioni A, Balafa O, Pappas K, Spanos G, Pelidou SH, Siamopoulos KC. Risk factors for cognitive dysfunction in CKD and hypertensive subjects. Int Urol Nephrol. 2013;45:1637-46.

41. Masoumi A, Goldenson B, Ghirmai S, Avagyan H, Zaghi J, Abel K, Zheng X, Espinosa-Jeffrey A, Mahanian M, et al. 1alpha,25-dihydroxyvitamin D3 interacts with curcuminoids to stimulate amyloid-beta clearance by macrophages of Alzheimer's disease patients. J Alzheimer's Dis. 2009;17:70317.

42. Mizwicki MT, Menegaz D, Zhang J, Barrientos-Durán A, Tse S, Cashman JR, Griffin PR, Fiala M. Genomic and nongenomic signaling induced by $1 \alpha, 25(\mathrm{OH}) 2$-vitamin $\mathrm{D} 3$ promotes the recovery of amyloid- $\beta$ phagocytosis by Alzheimer's disease macrophages. J Alzheimer's Dis. 2012;29:51-62.

43. Dursun E, Gezen-Ak D, Yilmazer S. A novel perspective for Alzheimer's disease: vitamin $\mathrm{D}$ receptor suppression by amyloid- $\beta$ and preventing the amyloid- $\beta$ induced alterations by vitamin D in cortical neurons. J Alzheimer's Dis. 2011;23:207-19.

44. Briones TL, Darwish H. Vitamin D mitigates age-related cognitive decline through the modulation of pro-inflammatory state and decrease in amyloid burden. J Neuroinflammation. 2012;9.

45. Briones TL, Darwish H. Decrease in age-related tau hyperphosphorylation and cognitive improvement following vitamin D supplementation are associated with modulation of brain energy metabolism and redox state. Neuroscience. 2014;262:143-55.

46. Tian A, Ma H, Cao X, Zhang R, Wang X, Wu B. Vitamin D Improves Cognitive Function and Modulates Th17/T reg Cell Balance After Hepatectomy in Mice. Inflammation. 2014;

47. Annweiler C, Brugg B, Peyrin J-M, Bartha R, Beauchet O. Combination of memantine and vitamin $\mathrm{D}$ prevents axon degeneration induced by amyloidbeta and glutamate. Neurobiol Aging. 2014;35:331-5.

48. Balion C, Griffith LE, Strifler L, Henderson M, Patterson C, Heckman G, Llewellyn DJ, Raina P. Vitamin D, cognition, and dementia: a systematic review and meta-analysis. Neurology. 2012;79:1397-405.

49. Annweiler C, Llewellyn DJ, Beauchet O. Low serum vitamin D concentrations in Alzheimer's disease: a systematic review and metaanalysis. J Alzheimer's Dis. 2013;33:659-74.

50. Annweiler C, Montero-Odasso M, Llewellyn DJ, Richard-Devantoy S, Duque $\mathrm{G}$, Beauchet $\mathrm{O}$. Meta-analysis of memory and executive dysfunctions in relation to vitamin D. J Alzheimer's Dis. 2013;37:147-71.

51. Etgen T, Sander D, Bickel H, Sander K, Förstl H. Vitamin D deficiency, cognitive impairment and dementia: a systematic review and meta-analysis. Dement Geriatr Cogn Disord. 2012;33:297-305.

52. Dickens AP, Lang IA, Langa KM, Kos K, Llewellyn DJ. Vitamin D, cognitive dysfunction and dementia in older adults. CNS Drugs. 2011;25:629-39.

53. Llewellyn DJ, Lang IA, Langa KM, Muniz-Terrera G, Phillips CL, Cherubini A, Ferrucci L, Melzer D. Vitamin D and risk of cognitive decline in elderly persons. Arch Intern Med. 2010;170:1135-41.

54. Slinin Y, Paudel M, Taylor BC, Ishani A, Rossom R, Yaffe K, Blackwell T, Lui L-Y, Hochberg M, Ensrud KE. Association between serum 25(OH) vitamin D and the risk of cognitive decline in older women. J Gerontol A Biol Sci Med Sci. 2012;67:1092-8.

55. Wilson VK, Houston DK, Kilpatrick L, Lovato J, Yaffe K, Cauley J a, Harris TB, Simonsick EM, Ayonayon HN, et al. Relationship between 25-hydroxyvitamin D and cognitive function in older adults: the Health, Aging and Body Composition Study. J Am Geriatr Soc. 2014;62:636-41.

56. Toffanello ED, Coin A, Perissinotto E, Zambon S, Sarti S, Veronese N, De Rui M, Bolzetta F, Corti M-C, et al. Vitamin D deficiency predicts cognitive decline in older men and women: The Pro.V.A. Study. Neurology. 2014;
57. Perna L, Mons U, Kliegel M, Brenner H. Serum 25-hydroxyvitamin D and cognitive decline: a longitudinal study among non-demented older adults. Dement Geriatr Cogn Disord. 2014;38:254-63.

58. Breitling LP, Perna L, Müller H, Raum E, Kliegel M, Brenner H. Vitamin $\mathrm{D}$ and cognitive functioning in the elderly population in Germany. Exp Gerontol. 2012;47:122-7.

59. Slinin Y, Paudel ML, Taylor BC, Fink HA, Ishani A, Canales MT, Yaffe K, Barrett-Connor E, Orwoll ES, et al. 25-Hydroxyvitamin D levels and cognitive performance and decline in elderly men. Neurology. 2010;74:33-41.

60. Granic A, Hill TR, Kirkwood TBL, Davies K, Collerton J, Martin-Ruiz C, von Zglinicki T, Saxby BK, Wesnes K a, et al. Serum 25-hydroxyvitamin D and cognitive decline in the very old: the Newcastle 85+ Study. Eur J Neurol. 2014;25:1-11.

61. Annweiler C, Rolland Y, Schott AM, Blain H, Vellas B, Beauchet O. Serum vitamin $\mathrm{D}$ deficiency as a predictor of incident non-Alzheimer dementias: a 7-year longitudinal study. Dement Geriatr Cogn Disord. 2011;32:273-8.

62. Afzal S, Bojesen SE, Nordestgaard BG. Reduced 25-hydroxyvitamin D and risk of Alzheimer's disease and vascular dementia. Alzheimer's Dement. 2014;10:296-302.

63. Littlejohns TJ, Henley WE, Lang IA, Annweiler C, Beauchet O, Chaves PHM, Fried L, Kestenbaum BR, Kuller LH, et al. Vitamin D and the risk of dementia and Alzheimer disease. Neurology. 2014;83:920-8.

64. Knekt P, Sääksjärvi K, Järvinen R, Marniemi J, Männistö S, Kanerva N, Heliövaara M. Serum 25-hydroxyvitamin D concentration and risk of dementia. Epidemiology. 2014;25:799-804.

65. Graf CE, Rossi C, Giannelli S V, Nobari BH, Gold G, Herrmann FR, Zekry D. Vitamin D is not associated with cognitive status in a cohort of very old hospitalized patients. J Alzheimer's Dis. 2014;42 Suppl 3:S53-61.

66. Annweiler C, Rolland Y, Schott AM, Blain H, Vellas B, Herrmann FR, Beauchet $\mathrm{O}$. Higher vitamin $\mathrm{D}$ dietary intake is associated with lower risk of Alzheimer's Disease: a 7-year follow-up. J Gerontol A Biol Sci Med Sci. 2012;1-7.

67. Przybelski R, Agrawal S, Krueger D, Engelke JA, Walbrun F, Binkley $\mathrm{N}$. Rapid correction of low vitamin D status in nursing home residents. Osteoporos Int. 2008;19:1621-8.

68. Stein MS, Scherer SC, Ladd KS, Harrison LC. A randomized controlled trial of high-dose vitamin D2 followed by intranasal insulin in Alzheimer's disease. J Alzheimer's Dis. 2011;26:477-84.

69. Annweiler C, Fantino B, Gautier J, Beaudenon M, Thiery S, Beauchet O. Cognitive effects of vitamin D supplementation in older outpatients visiting a memory clinic: a pre-post study. J Am Geriatr Soc. 2012;60:793-5.

70. Rossom RC, Espeland M a, Manson JE, Dysken MW, Johnson KC, Lane DS, LeBlanc ES, Lederle FA, Masaki KH, Margolis KL. Calcium and vitamin D supplementation and cognitive impairment in the women's health initiative. J Am Geriatr Soc. 2012;60:2197-205.

71. Manson JE, Bassuk SS, Lee I-M, Cook NR, Albert MA, Gordon D, Zaharris E, Macfadyen JG, Danielson E, et al. The VITamin D and OmegA-3 TriaL (VITAL): rationale and design of a large randomized controlled trial of vitamin $\mathrm{D}$ and marine omega-3 fatty acid supplements for the primary prevention of cancer and cardiovascular disease. Contemp Clin Trials. 2012;33:159-71.

72. Annweiler C, Montero-Odasso M, Muir SW, Beauchet O. Vitamin D and brain imaging in the elderly: should we expect some lesions specifically related to hypovitaminosis D? Open Neuroimag J. 2012;6:16-8.

73. Buell JS, Weiner DE, Tucker L, Usda JM. 25-Hydroxyvitamin D, dementia, and cerebrovascular pathology in elders receiving home services. Neurology. 2010;74:18-26.

74. Annweiler C, Annweiler T, Bartha R, Herrmann FR, Camicioli R, Beauchet O. Vitamin D and white matter abnormalities in older adults: a cross-sectional neuroimaging study. Eur J Neurol. 2014;

75. Sakurai T, Ogama N, Toba K. Lower vitamin D is associated with white matter hyperintensity in elderly women with Alzheimer's disease and amnestic mild cognitive impairment. J Am Geriatr Soc. 2014;62:1993-4.

76. Hooshmand B, Lökk J, Solomon A, Mangialasche F, Miralbell J, Spulber G, Annerbo S, Andreasen N, Winblad B, et al. Vitamin D in relation to cognitive impairment, cerebrospinal fluid biomarkers, and brain volumes. J Gerontol A Biol Sci Med Sci. 2014;1-7.

77. Annweiler C, Montero-Odasso M, Hachinski V, Seshadri S, Bartha R, Beauchet $\mathrm{O}$. Vitamin D concentration and lateral cerebral ventricle volume in older adults. Mol Nutr Food Res. 2013;57:267-76.

78. Michos ED, Carson KA, Schneider ALC, Lutsey PL, Xing L, Sharrett AR, Alonso A, Coker LH, Gross M, et al. Vitamin D and subclinical cerebrovascular disease: the atherosclerosis risk in communities brain magnetic resonance imaging study. JAMA Neurol. 2014;71:863-71.

79. Snellman G, Melhus H, Gedeborg R, Byberg L, Berglund L, Wernoth L, Michaëlsson K. Determining vitamin D status: a comparison between commercially available assays. Gagnier JJ, editor. PLoS One. 2010;5.

80. Zerwekh JE. Blood biomarkers of vitamin D status. Am J Clin Nutr. 2008;87:1087S - 91S.

81. Lai JKC, Lucas RM, Banks E, Ponsonby A-L. Variability in vitamin D assays impairs clinical assessment of vitamin D status. Intern Med J. 2012;42:43-50.

. Binkley N, Sempos CT. Standardizing vitamin d assays: the way forward. J 
Bone Miner Res. 2014;29:1709-14.

83. Powe CE, Ricciardi C, Berg AH, Erdenesanaa D, Collerone G, Ankers E, Wenger J, Karumanchi SA, Thadhani R, Bhan I. Vitamin D-binding protein modifies the vitamin D-bone mineral density relationship. J Bone Miner Res. 2011;26:1609-16.

84. Johnsen MS, Grimnes G, Figenschau Y, Torjesen P a, Almås B, Jorde R. Serum free and bio-available 25-hydroxyvitamin D correlate better with bone density than serum total 25-hydroxyvitamin D. Scand J Clin Lab Invest. 2014;74:177-83.

85. Autier P, Boniol M, Pizot C, Mullie P. Vitamin D status and ill health: a systematic review. Lancet Diabetes Endocrinol. 2014;2:76-89.

86. Farid K, Volpe-Gillot L, Petras S, Plou C, Caillat-Vigneron N, Blacher J. Correlation between serum 25-hydroxyvitamin D concentrations and regional cerebral blood flow in degenerative dementia. Nucl Med Commun. 2012;33:1048-52.
87. Bowman GL, Silbert LC, Howieson D, Dodge HH, Traber MG, Frei B, Kaye JA, Shannon J, Quinn JF. Nutrient biomarker patterns, cognitive function, and MRI measures of brain aging. Neurology. 2012;78:241-9.

88. Annweiler C, Beauchet O, Bartha R, Graffe A, Milea D, Montero-Odasso M. Association between serum 25-hydroxyvitamin D concentration and optic chiasm volume. J Am Geriatr Soc. 2013;61:1026-8.

89. Annweiler C, Beauchet O, Bartha R, Hachinski V, Montero-Odasso M. Vitamin D and caudal primary motor cortex: a magnetic resonance spectroscopy study. PLoS One. 2014;9:e87314.

90. Walhovd KB, Storsve AB, Westlye LT, Drevon CA, Fjell AM. Blood markers of fatty acids and vitamin D, cardiovascular measures, body mass index, and physical activity relate to longitudinal cortical thinning in normal aging. Neurobiol Aging. 2014;35:1055-64. 